\title{
Enzymatic variability and phylogenetic relatedness among Triatoma infestans, $T$. platensis, T. delpontei and T. rubrovaria
}

\author{
J. PEREIRA $\dagger$, J. P. DUJARDIN*, R. SALVATELLA $\ddagger$ \& M. TIBAYRENC \\ UMR CNRS-ORSTOM 9926 'Génétique Moléculaire des Parasites et des Vecteurs', BP 5045, 34032, Montpellier \\ cedex 1, France and $\ddagger$ Departamento de Parasitología, Instituto de Higiene, Universidad de la República, BP 11600, \\ Montevideo, Uruguay.
}

\begin{abstract}
Four congeneric species of triatomine bugs, Triatoma platensis, T. delpontei, T. rubrovaria and T. infestans, were examined by multilocus enzyme electrophoresis. These four species are distributed sympatrically throughout Argentina, Paraguay and Uruguay, and were found to be closely related according to their known ethological, ecological and morphological traits. In order to evaluate previous hypotheses concerning the phylogenetic branching within this group, isoenzyme patterns were submitted to classical phenetic and genetic clustering analysis. Results are discussed in the light of occasional natural gene flow between $T$. infestans and T. platensis, and indicate that ecology is the main factor explaining both their present status and their morphological differentiation.
\end{abstract}

Keywords: Chagas disease, genetic distance, isoenzymes, Triatominae, Uruguay.

\section{Introduction}

In their major review of the biosystematics of Triatominae, Usinger et al. (1966) grouped together the four species considered in the present work, on the basis of their morphological, behavioural and ecological similarities. The four species share many common features, particularly $T$. platensis and $T$. delpontei (Lent \& Wygodzinsky, 1979), although they are not difficult to distinguish by overt morphological characteristics such as connexival colour patterns and degree of pilosity (Lent \& Wygodzinsky, 1979). Triatoma infestans is an important vector of American trypanosomiasis (Chagas disease) and is almost exclusively associated with humans and domestic animals. It is widely distributed in the southern part of Latin America (Argentina, Bolivia, Brazil, Paraguay, Peru and Uruguay) and typically found in the cracks and crevices of poor quality rural houses, emerging at night to feed on the people and domestic animals sleeping there. In contrast, T. platensis and T. delpontei are ornithophilic arboreal species, without relevance for the

*Correspondence.

†Present address: Sección Genética Evolutiva, Facultad de Ciencias, Universidad de la República, BP 11200, Montevideo, Uruguay. transmission of human Chagas disease (Salvatella, 1986a,b, 1987); T. platensis commonly infests the woven stick nests of furnariid weaver birds (Anumbius spp.) in northern Argentina, Paraguay, Uruguay and southern Brazil, but has also been found in peridomestic habitats such as chicken coops. Triatoma delpontei seems more ecologically restricted, found almost exclusively in woven stick nests of colonial monk parrots (Myiopsitta monarcha), but occupying a similar geographical range to $T$. platensis.

The fourth member of the group, T. rubrovaria, is usually found amongst limestone outcrops in Uruguay and southern Brazil, often forming abundant colonies feeding on a wide range of rupicoline vertebrates (Salvatella, 1988). However, it is increasingly reported in domestic and peridomestic habitats in parts of Uruguay where $T$. infestans has been eliminated by Chagas vector control activities (Salvatella et al., 1991b; Salvatella, 1993).

Considering a large number of morphological, physiological and behavioural characteristics, Usinger et al. (1966) concluded that T. platensis and T. delpontei were more closely related to each other than to $T$. infestans. They suggested that $T$. platensis and $T$. delpontei were 'most probably derived one from the other or from a direct common ancestor'. 
Nevertheless, epidemiological considerations have led other authors to suggest that $T$. infestans may have arisen as a domesticated form of $T$. platensis (Carcavallo et al., 1986). Since then, no more data have been added to improve our knowledge about this closely linked species group, except for a recent study relating $T$. infestans with $T$. platensis on the basis of their chromosome C-banding (Panzera et al., 1995). Isoenzyme markers, although they are considered to be more suitable for phylogenetic reconstruction than phenotypic traits (Richardson et al., 1986), were not applied.

The goal of the present work was to clarify the relationships within this group of species by using multilocus enzyme electrophoresis, and to see if the enzyme patterns could be related to ecological associations of the four species.

\section{Materials and methods}

\section{Insects}

The origins of the 1044 insects used in this study are as follows.

Triatoma infestans One hundred and thirty-one specimens from Uruguay were collected from domestic and peridomestic habitats in the Departments of Soriano (south of Uruguay) and Rivera (North of Uruguay). The results obtained from these specimens were then plotted together with data previously obtained by Dujardin (1990) on 777 Bolivian $T$. infestans using similar techniques.

Triatoma rubrovaria Thirty-one specimens were collected from peridomestic habitats in the Department of Artigas, Uruguay. Most were collected by the National Chagas Control Programme between 1989 and 1990.

Triatoma platensis Ninety-two specimens were studied: 82 were collected from nests of Anumbius annumbi in the Palmar de Quebracho region, Department of Paysandú, Uruguay); the remaining 10 were collected from similar nests in the Barra do Quaraí region, State of Río Grande do Sul, Brazil (Salvatella et al., 1991a).

Triatoma delpontei Thirteen specimens were studied, of which 10 were laboratory-reared adults representing the fourth generation of material originally collected in Santiago del Estero, Argentina. Three further specimens were captured in a monk parrot nest in the Department of Artigas, Uruguay.

\section{Enzyme electrophoresis}

Analysis was performed by electrophoretic separation of isoenzymes on cellulose acetate plates (Helena Laboratories, Beaumont, TX). Seventeen enzyme systems were assayed, as follows: aconitase (aconitate hydratase, EC 4.2.1.3, ACON); aspartate aminotransferase (also known as glutamate-oxaloacetate transaminase) (EC 2.6.1.1, GOT); diaphorase (EC 1.8.1.4, DIA); glyceraldehyde-3-phosphate dehydrogenase (EC 1.2.1.12, GAPD); glucose6-phosphate dehydrogenase (EC 1.1.1.49, G6PDH); glycerol-3-phosphate dehydrogenase (EC 1.1.1.8, GPD); glucose-6-phosphate isomerase (EC 5.3.1.9, GPI); hexokinase (EC 2.7.1.1, HK); isocitrate dehydrogenase (EC 1.1.1.42, IDH); leucine aminopeptidase (cytosol aminopeptidase) (EC 3.4.11.1, LAP); malate dehydrogenase (EC 1.1.1.37, MDH); malate dehydrogenase (malic enzyme) (EC 1.1.1.40, $\mathrm{ME}$ ); peptidase 1 (EC 3.4.11, PEP-1; leucyl-leucylleucine substrate); peptidase 2 (EC 3.4.11, PEP-2; leucyl-L-alanine substrate); peptidase 3 (EC 3.4.11, PEP-3; L-leucine-L-tyrosine substrate); phosphoglucomutase [EC 5.4.2.2 (formerly EC 2.7.5.1), PGM]; and 6-phosphogluconate dehydrogenase (EC 1.1.1.44, 6-PGDH).

Starved fifth instar nymphs and adults (both males and females) were used. Head and thorax samples were ground in liquid nitrogen with a glass mortar in an Eppendorf tube. Stabilizer was added (Godfrey \& Kilgour, 1976) and the rest of the material was cut with entomological scissors until all the pieces has been crushed. Other conditions for sample preparation, electrophoresis and enzyme staining were as previously described by Dujardin \& Tibayrenc (1985) except for GOT, HK, GAPD and DIA, which were processed following the techniques of Richardson et al. (1986).

\section{Statistical methods}

We characterized each specimen by its multilocus genotype (MLG), represented by the different allelic combinations (genotypes) found at all identified putative loci. For the whole sample, we could retain 53 different MLGs (Table 1) which were used for statistical analysis.

Our cladistic approach (Fig. 1) was based on the maximum parsimony method ('Wagner tree') of Farris (1970), and was computed using the software package PHYLIP 3.4 (Felsenstein, 1985). The 'independent alleles' coding of electrophoretic data (Agnese, 1989) was used, whereby each allele is considered as a character and the character-states 
Table 1 The isoenzyme patterns of the 53 different multilocus genotypes (MLGs) found among the four Triatoma species studied

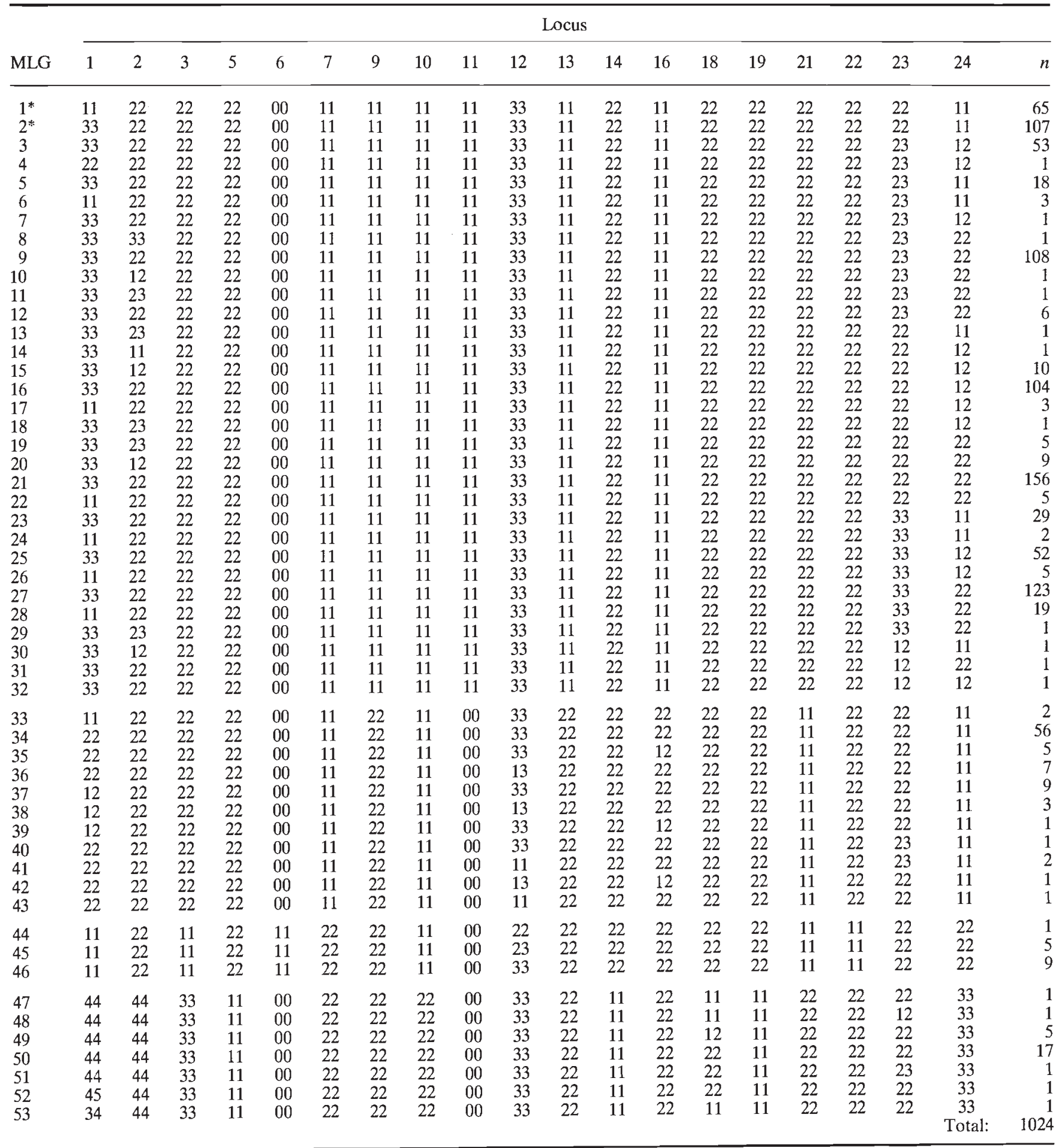

1, Gpd-1; 2, Gpd-2; 3, Acon; 5, Dia-2; 6, Dia-3; 7, Dia-4; 9, Hk; 10, Idh-1; 11, Idh-2; 12, Lap-1; 13, Lap-2; 14, Mdh-1; 16, Me-1; 18, Pep-1; 19, Pep-2; 21, Pep-4; 22, Gpi; 23, Pgm; 24, 6-Pgdh. Loci numbered 4, 8, 15, 17 and 20 (Dia-1, G-6-pdh, Mdh-2, Me-2 and Pep-3,

respectively) are not shown as they did not vary among species. Numbers $11,12,22,23,33$, etc. represent the symbols of each allele $(1,2$, 3 , etc.) constituting different genotypes. 00 denotes that no bands were detected.

MLGs 1-32, T. infestans; MLGs 33-43, T. platensis; MLGs 44-46, T. delpontei; MLGs 47-53, T. rubrovaria.

$n=$ total number of individuals recorded for a given MLG.

${ }^{*}$ The two genotypes are present both in Uruguay and Bolivia, i.e. there is no specific genotype of $T$. infestans in Uruguay. 


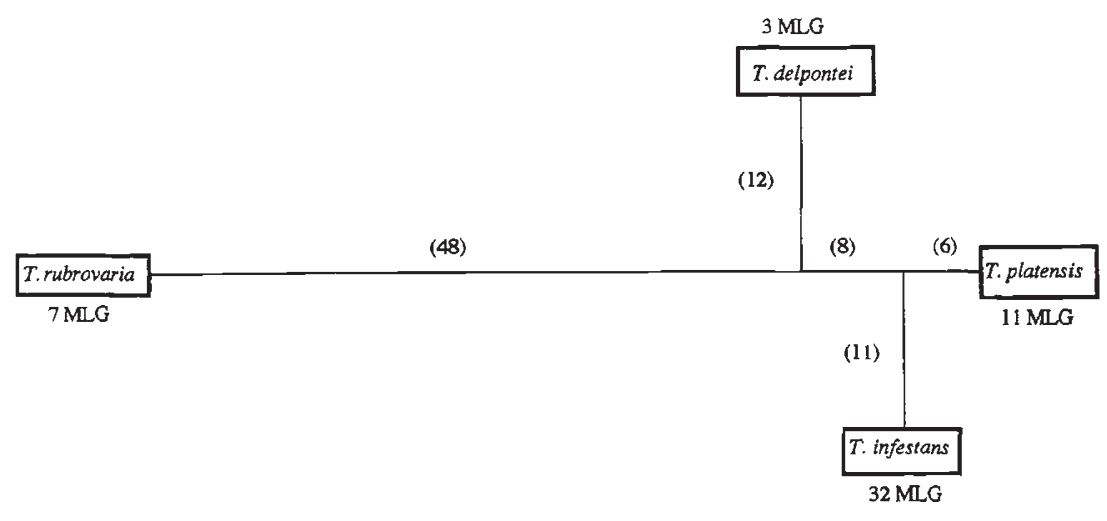

Fig. 1 An unrooted Wagner tree depicting the phylogenetic relationships among the four Triatoma species under study (Uruguayan and Bolivian specimens of $T$. infestans share common genotypes, so they are included within the same T. infestans box). The numbers in brackets refer to the patristic (or evolutionary) distances among the species. The patristic distance between any two species is given by the sum of the patristic distances quoted along the branches that join these two species. For example, the patristic distance between $T$. delpontei and $T$. platensis is $12+8+6=26$. It appears that the latter two species are not particularly closely related to each other, compared with the T. infestans and T. platensis pair, separated by patristic distance $11+6=17$. The number of different multilocus genotypes (MLGs) recorded in each species is given by the species name. Triatoma infestans from Bolivia and from Uruguay were not separated on this figure because of their common MLGs, MLG 1 and MLG 2. are 'present' or 'absent'. To evaluate the robustness of the distance-Wagner trees, we used the bootstrap procedure of Felsenstein (1985).

Phenetic analysis (Fig. 2) was visualized by constructing a UPGMA dendrogram (Sokal \& Michener, 1958) derived from the matrix of standard genetic distances (Nei, 1972) computed from the array of 53 MLG. This analysis gave similar results, either taking account of sample size, or not.

\section{Results}

\section{Technical results}

Eleven enzyme systems (GPD, ACON, G6PDH, IDH, LAP, MDH, ME, PEP-1, PEP-2, PEP-3, GPI, PGM and 6-PGDH) were revealed as in Dujardin \& Tibayrenc (1985), except for ACON where only one band could be scored. PEP-1, PEP-2 and PEP-3 revealed the same bands with different intensities. Two additional enzyme systems also gave reproducible patterns (HK and DIA). GAPD and GOT activity was too weak or sporadic to allow reliable interpretation. GAPD and GOT activity was too weak or sporadic to allow reliable interpretation.

\section{Isoenzymatic polymorphism}

Locus numbering was according to Dujardin \& Tibayrenc (1985), except for GPD which clearly revealed two loci, and $\mathrm{ACON}$ which revealed only one. Because the DIA and the PEP systems each gave four loci, and GPD, IDH, LAP, MDH and ME each gave two, the studied set of enzymes represented a total of 24 genetic loci (Dujardin \& Tibayrenc, 1985; Frias \& Kattan, 1989). Over the whole set of four species, seven loci appeared to be variable, namely Gpd-1, Gpd-2, Lap-1, Me-1, 6-Pgdh, Pgm and Pep-1 (0.29 of the total loci). Only one locus ( $G p d-1)$ was variable in the Uruguayan populations of $T$. infestans (0.04 of the total loci), compared with three in the Bolivian specimens (Gpd-2, 6-Pgdh and Pgm, i.e. 0.13 of the total loci) (Dujardin \& Tibayrenc, 1985). Four loci (Gpd-1, Lap-1, Me-1 and Pgm) varied in the sample of $T$. platensis $(0.17$ of the total loci), and three (Gpd-1, Pep-1 and Pgm) in T. rubrovaria ( 0.13 of the total loci). One polymorphic locus (Lap-1) (0.04 of the total loci) was detected in $T$. delpontei (see Table 1). The unbiased estimate of gene diversity (or expected heterozygosity, $H$ ) (Nei, 1987) and its standard error were computed for the 
Fig. 2 A UPGMA dendrogram based on Nei's unbiased genetic distance, illustrating the genetic relationships among the four Triatoma species under study. B, Bolivia; U, Uruguay.

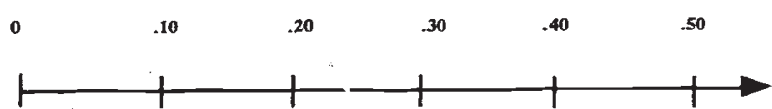

T. infestans $B$

T. infestans $U$

T. platensis

T. deipontei

T. rubrovaria

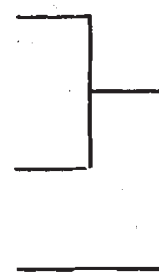

full sample of four different species $(H=0.076 \pm 0.031)$ and for each species (mean $=0.028 \pm 0.019)$. supported by the bootstrap analysis where these two species appeared as the most closely related pair 87 times out of 100 replicates (Fig. 1).

\section{Discussion}

\section{Intraspecific analysis}

With more than 20 loci, at least $20-30$ individuals should be examined at each locus (Nei, 1987) in order to get reliable conclusions about the isoenzyme variability. In our study only the $T$. delpontei sample did not fit this condition. Thus, the apparently low polymorphism in this species (calculated heterozygosity $H=0.019 \pm 0.019$ ) might be attributed to our small sample size of 13 specimens) although, as pointed out by Nei (1987), the most important factor in minimizing the variance of genetic distance estimates is the number of loci examined rather than the number of individuals. In the case of $T$. delpontei, however, the apparently low polymorphism could also be attributed to the origins of the specimens, most of which were from a fourth generation laboratory colony formed from an unknown number of founders. However, it is worth noting that among the same set of 24 loci, the same unique variable locus (Lap-1) was found in the laboratory-reared specimens from Argentina, originally collected from Santiago del Estero, and in the silvatic specimens from Uruguay (nearly $1000 \mathrm{~km}$ distant). It seems possible, therefore, that the low rate of polymorphism recorded here may be a general feature of $T$. delpontei.

The calculated heterozygosity was also low for the three other species studied here, ranging from $0.020 \pm 0.011$ for $T$. platensis to $0.023 \pm 0.017$ for $T$. 
rubrovaria and $0.050 \pm 0.029$ for $T$. infestans. This is in accordance with studies on other species of Triatominae indicating a trend towards low isozymic polymorphism amongst Triatominae (Dujardin \& Tibayrenc, 1985; Harry, 1992; Harry et al., 1992; Solano et al. 1996).

Another notable result is the pattern of genetic variation observed in three of the four species for the GPD system. For insects this enzyme is generally involved in metabolic functions associated with flight muscle activity, and tends to be monomorphic or poorly polymorphic in most Diptera (Pasteur \& De Stordeur, 1976; Coyne et al., 1979; Mery et al., 1979; Lakovaara \& Keranen, 1980). The relatively high variability at these loci in $T$. infestans has been tentatively explained by the low level of flight activity in this species (Dujardin et al., 1988).

The present data confirm this tendency to polymorphism at these loci in two additional triatomine species, $T$. platensis and T. rubrovaria, which exhibited complex variable isozyme patterns similar to those previously described in $T$. infestans (Dujardin, 1990). The flight behaviour of these two species is not known, but we suspect it may be similar to that of $T$. infestans because all three species tend to live in close association with their vertebrate hosts.

\section{Interspecific comparisons}

According to Richardson et al. (1986, p. 55), no more than two or three individuals need to be sampled to represent a population in a phylogenetic study, and additional samples need only be taken where there is evidence of considerable genetic variation within a species. Indeed, dendrograms from subsamples are most likely to resemble the full data set when heterozygosity levels within taxa are low, allele frequencies are near zero or one, and there are clear patterns of fixed or nearly fixed alleles unique to certain groups and subgroups of taxa (Archie et al., 1989). This description appears to fit our material, so that our within-species sample sizes (from 13 to 1044 specimens) could be considered as representative.

The genetic distance between $T$. infestans and $T$. platensis was very low compared to that between $T$. platensis and $T$. delpontei (see Figs 1 and 2) even though there is no doubt that these are definitely separate species (Lent \& Wygodzinsky, 1979).

Two hypotheses, which are not mutually exclusive, can be advanced to explain the low genetic distance between $T$. infestans and T. platensis. The two species may have diverged recently from each other or from a common ancestor, or their actual phylogenetic divergence may be minimized by persistent gene flow in the field. In support of the first hypothesis are the conclusions of a recent cytogenetical study showing more similarity between T. platensis and $T$. infestans than between $T$. platensis and $T$. delpontei (Panzera et al., 1995). Another indication of recent common ancestry between $T$. infestans and $T$. platensis is their interfertility. In this respect, our data are fully consistent with previous studies which recorded complete interfertility between $T$. platensis and $T$. infestans, whereas partial sterility was found between T. platensis and T. delpontei (Abalos, 1948; Franca, 1985 ) and production of sterile hybrids was observed between T. infestans and T. rubrovaria (Usinger et al., 1966).

The close kinship revealed in the present work by isozyme analysis between $T$. infestans and $T$. platensis, and the results of our phylogenetic analysis, do not support the hypothesis of a 'common ancestor' for $T$. delpontei and T. platensis, despite the fact that these two species are similar both morphologically (Lent \& Wygodzinsky, 1979) and ecologically (Usinger et al., 1966). Moreover, the present data also suggest that $T$. infestans and $T$. platensis are more closely related to each other than to either of the two other species. Nevertheless, the phylogenetic reconstruction proposed here should be corroborated by further studies involving both larger samples and additional genetic markers.

The second hypothesis is that apparent phylogenetic clustering could be drastically modified by unequal gene flow that could exist even between different species. The geographical range of $T$. delpontei represents a relatively small zone within the range of $T$. platensis. Both species are sympatric, even being found in different nests on the same tree. In spite of this sympatry and their partial fertility, no hybrids seem to occur in nature, or if they do, they must be very rare. Gene flow would in any case be reduced by 50 per cent owing to the sterility of a mating between $T$. platensis females and $T$. delpontei males. Contrasting with this partial reproductive isolation and the probable absence or scarcity of natural hybrids, complete laboratory fertility and the occurrence of natural hybrids have been found between T. platensis and T. infestans (Usinger et al., 1966; Franca, 1985). Indeed, T. platensis occasionally enters peridomestic habitats such as chicken coops, which in Uruguay are frequently invaded by $T$. infestans, and natural hybrids may occur (Usinger et al., 1966). Two arguments lending support to the hypothesis that genetic distances reflect gene flow more than ancestral relationships would be the following: (i) when considering T. infestans from 
Bolivia (a country where $T$. platensis has not been recorded), the genetic distance between $T$. infestans and $T$. platensis is slightly larger (unbiased $D_{\mathrm{s}}=0.12$ ) than when considering Uruguayan $T$. infestans (unbiased $D_{\mathrm{s}}=0.094$ ); and (ii) when comparing genetic distances on the one hand, and biological traits such as morphology, ecology and interfertility on the other, more apparent concordance is observed between genetic distances and interfertility (genetic distances increase while interfertility declines). Nevertheless, these arguments remain speculative, and from the present data it is not possible to decide between these two hypotheses (recent ancestry between $T$. infestans and T. platensis, or actual ancestry masked by persistent gene flow between them).

\section{Speciation and ecology}

The fact that genetic barriers to gene exchange have not developed between $T$. platensis and $T$. infestans implies that their status as distinct species is almost entirely based upon their ecological separation. Although T. platensis is clearly able to invade human dwellings and peridomestic habitats by feeding on poultry, it maintains its association with wild birds as does $T$. delpontei. It thus appears that $T$. platensis, which has developed all the morphological features typical of arboreal triatomines like $T$. delpontei, has acquired a highly specialized adaptation to bird nests: this, and the competition with domiciliary $T$. infestans, might handicap its adaptation to the human environment. According to this point of view, the morphological proximity of $T$. platensis and $T$. delpontei would be mainly the consequence of convergence and not of common ancestry. On the other hand, the same ecological adaptations could be regarded as isolating mechanisms playing a role in speciation.

These ecological specificities and the non-negligible Nei's genetic distance are good arguments for maintaining $T$. platensis and $T$. infestans as distinct species. In this regard, their interfertility and the probable natural gene flow between them could modify this situation in some cases of ecological perturbations, lowering their present separation. Another indication that ecology could play an important role in triatomine speciation processes are the observations that (i) no natural hybrids are observed between $T$. delpontei and $T$. platensis, which are never found in the nests of the same bird species, whereas (ii) natural hybrids are occasionally observed between $T$. infestans and $T$. rubrovaria
(Lent \& Wygodzinsky, 1979) which sometimes do coexist in human habitats.

We conclude therefore, in agreement with Usinger et al. (1966), that ecological factors may be the main force acting in the speciation of Triatominae. However, in disagreement with the same authors, our results are compatible with the hypothesis that morphological similarities in Triatominae are largely the consequence of convergence, reflecting the ecological niche more than common ancestry. If this conclusion is true, morphology should be regarded with caution as the main criterion for phylogenetic studies in Triatominae.

\section{Acknowledgements}

We are grateful to Dr G. Lanotte from the Laboratoire d'Ecologie Médicale et de Pathologie Parasitaire, Faculté de Médicine, Montpellier, France, for her valuable help in the phylogenetic analysis of MLGs; Dr C. J. Schofield of the London School of Hygiene and Tropical Medicine for providing $T$. delpontei specimens, and the National Chagas Control Programme technicians for their technical support. This work was supported by the EC Commission (Grant No. TS3-CT91-0029) and by an EC postdoctoral fellowship (B/CI1*-913124) awarded to J. P.

\section{References}

ABalos, J. w. 1948. Sobre hibridos naturales y experimentales de Triatoma. Anal. Inst. Med. Reg., 2, 209-223. AGNese, J. F. 1989. Différenciation Génétique de Plusieurs Espèces de Siluriformes Ouest-Africains Ayant un Intérêt pour la Pêche et L'aquaculture. Ph.D. Thesis, Université des Sciences et Techniques du Languedoc, Académie de Montpellier, France.

ARCHIE, J. W., SIMON, C. AND MARTIN, A. 1989. Small sample size does decrease the stability of dendrograms calculated from allozyme-frequency data. Evolution, 43, $678-683$.

COYNE, J. A., EANES, W. F., RAMSHAW, J. A. M. AND KOEHN, R. K. 1979. Electrophoretic heterogeneity of $\alpha$-glycerophosphate dehydrogenase among many species of Drosophila. Syst. Zool., 28, 164-175.

Dujardin, J. P. 1990. Intérêt de la Génétique des Populations dans l'Etude des Vecteurs de la Trypanosomiase Américaine. Ph.D. Thesis, University of Liège, Belgium.

DuJARDin, J. P. AND TIBAYRENC, M. 1985. Etude de 11 enzymes et données de génétique formelle pour 19 loci enzymatiques chez Triatoma infestans (Hemiptera: Reduviidae). Ann. Soc. Belg. Méd. Trop., 65, 271-280.

DUJARDin, J. P., TIBAYRENC, M., MARCONDEZ, C. B., 
CARDOZO, L., JORDAN, S. F. AND BERMUDEZ, H. 1988. Genetic variability of alpha-glycerophosphate dehydrogenase in Triatoma infestans (Hemiptera: Reduviidae). $V$ Reuniao sobre Pesquisa aplicada em doença de Chagas, Araxa, 3-5 November 1988, p. 82.

FARRIS, J. S. 1970. Methods for computing Wagner trees. Syst. Zool., 19, 83-92.

FELSENSTEIN, J. 1985. Confidence limits on phylogenies: an approach utilizing the bootstrap. Evolution, 39, 783-791.

FRANCA, M. 1985. Vectors in Uruguay. In: Carcavallo, R. U. and Tonn, R. J. (eds) Factores Biologicos y Ecologicos en la Enfermedad de Chagas, pp. 457-463. Ministerio de Salud, Buenos Aires.

FR1AS, D. AND KATTAN, F. 1989. Molecular taxonomic studies in Triatoma infestans (Klug, 1834) and Triatoma spinolai Porter, 1933 populations (Hemiptera: Triatominae). Acta Ent. Chilena, 15, 205-210.

GODFREY, D. G. AND KILGOUR, V. 1976. Enzyme electrophoresis characterizing the causative agent of Gambian trypanosomiasis. Trans. R. Soc. Trop. Med. Hyg., 71, 217-225.

HARry, M. 1992. Variabilité Génétique de Populations Vénézuéliennes de Rhodnius spp., Vectrices de Trypanosoma cruzi, Parasite Responsable de la Maladie de Chagas. Ph.D. Thesis, University of Paris VI.

HARRY, M., GALINDEZ, 1. AND CARIOU, M. L. 1992. Isozyme variability and differentiation between Rhodnius prolixus, $R$. robustus, and $R$. pictipes, vectors of Chagas disease in Venezuela. Med. Vet. Ent., 6, 37-43.

LAKOVAARA, S. AND KERÄNEN, L. 1980. Variation at the $\alpha-G p d h$ locus of drosophilids. Hereditas, 92, 251-258.

LENT, H. AND WYGODZINSKY, P. 1979. Revision of the Triatominae (Hemiptera, Reduviidae) and their significance as vectors of Chagas disease. Bull. Am. Mus. Nat. Hist., 163, 125-520.

MERY, A., PASTEUR, N. AND GUILVARD, E. 1979. Glutamateoxaloacétate transaminase et $\alpha$-glycérophosphate déshydrogénase chez le moustique Aedes (Ochlerotatus) caspius: génétique formelle et étude de populations. Can. J. Genet. Cytol., 21, 25-32.

NEl, M. 1972. Genetic distance between populations. Am. Nat., 106, 283-292.

NE1, M. 1987. Molecular Evolutionary Genetics. Columbia University Press, New York.

PANZERA, F., PEREZ, R., PANZERA, Y., ALVAREZ, F. SCVORTZOFF, E. AND SAlVATElla, R. 1995. Karyotype evolution in holocentric chromosomes of three related species of Triatominae (Hemiptera: Reduviidae). Chromosome Res., 3, 143-150.

PASTEUR, N. AND DE STORDEUR, E. 1976. L' $\alpha$-glycérophosphate-déshydrogénase du moustique Culex pipiens: génétique formelle, linkage et étude de populations. Genetica, 46, 319-326.

RICHARDSON, B. J., BAVERSTOCK, P. R. AND ADAMS, S. M. 1986. Allozyme Electrophoresis: a Handbook for Animal Systematics and Population Studies. Academic Press, Orlando, FL.

Salvatella, R. 1986a. Triatomineos del Uruguay. Rev. Med. Uruguay, 2, 106-113.

salvatella, R. 1986b. Triatoma delpontei (Romanha \& Abalos, 1947) (Hemiptera - Reduviidae). Nueva especie de Triatomineos para el Uruguay. Rev. Urug. de Pat. Clinica, 22, 58.

Salvatella, R. 1987. Distribución de Triatoma platensis Neiva, 1913. (Hemiptera - Triatominae) en Uruguay. Rev. Soc. Urug. Parasitol., 1, 51-56.

Salvatella, R. 1988. Aspectos de la interaccion de Homonota uruguayensis (Lacertilia, Gekkonidae) y $T$. rubrovaria (Blanchard, 1943) (Hemiptera, Triatominae) en sus habitats naturales. Reun. Iberoam. de Conserva. $y$ Zool. Vert., Soc. Zool. Urug. 5a. Montevideo, 56-60.

SAlvatella, R. 1993. Triatoma rubrovaria (Blanchard, 1843) (Hemiptera, Triatominae), vector secundario con potencial de intradomiciliación. Rev. da Soc. Bras. de Med. tropicale, 26, Suppl. II, 43-45.

SALVATElla, R., BASMADJIAN, Y., ROSA, R., MARTINeZ, M., MENDARO, G. AND CIVILA, E. 1991a. Hallazgo de Triatoma platensis Neiva, 1913 (Hemiptera, Triatominae) en el estado brasileño de "Río Grande do Sul". Rev. Inst. Méd. Trop. Sao Paulo, 33, 1-5.

SALVATELLA, R., CALEGARI, L., LOWINGER, M., BASMADJIAN, Y., ROSA, R., MENDARO, G. AND CIVILA, E. 1991b. Triatoma rubrovaria (Hemiptera, Triatominae) y su papel como vector secundario del ciclo domiciliario de Trypanosoma cruzi en Uruguay. Rev. Méd. Uruguay, 7, 45-50.

SOKAL, R. R. AND MICHENER, C. D. 1958. A statistical method for evaluating systematic relationships. Univ. Kans. Sci. Bull., 38, 1409-1438.

SOlANO, P., DUJARDiN, J. P., SCHOFIELD, C. J, ROMAÑA, C. AND TIBAYRENC, M. 1996. Isoenzymes as a tool for Rhodnius species identification. Res. Rev. Parasitol. (in press).

USINGER, R. L., WYGODZINSKY, P. AND RYCKMAN, R. 1966. The biosystematics of Triatominae. Ann. Rev. Ent., 11, 309-330. 